\title{
Numerical investigation on rigid and flexible pipelines embedded in granular and self-compacting materials
}

\author{
Khalid Abdel-Rahman ${ }^{1}$ (D) $\cdot$ Tim Gerlach $^{1} \cdot$ Martin Achmus $^{1}$
}

Received: 3 April 2020 / Accepted: 12 June 2020 / Published online: 24 June 2020

(c) The Author(s) 2020

\begin{abstract}
Self-compacting filling material or controlled low-strength material (CLSM) is a cementitious material which is liquid during filling, and it is used primarily as backfill, e.g., in trenches. Several products are currently used as CLSM such as flowable fill, controlled density fill, flowable mortar and low-strength plastic soil-cement. The low-strength requirement is necessary to allow for future excavation of CLSM. A two-dimensional numerical model was developed using the finite element system ABAQUS. In this model, the material behavior of granular soil and CLSM is described using an elasto-plastic constitutive model with Mohr-Coulomb failure criterion. Rigid and flexible pipes were modeled once embedded in sandy soil and once embedded in self-compacting material. The numerical model allows the modeling of the effect of hardening process on the overall behavior of the pipe-soil system. The main objective of this study is to investigate the behavior of rigid and flexible pipelines embedded in CLSM as a filling material numerically and to show advantages and disadvantages in comparison with the presently widely used filling materials like sand.
\end{abstract}

Keywords Self-compacting material (CLSM) $\cdot$ Finite element method $\cdot$ Mohr-Coulomb material model $\cdot$ Hardening process $\cdot$ Pipelines

\section{Introduction}

Controlled low-strength material (CLSM) is a self-compacted cementitious material used primarily as a backfill as an alternative to compacted fill. CLSM should not be considered as a type of low-strength concrete, but rather a self-compacted material with features similar to soil. At some sites, the use of self-compacting materials has proven to be beneficial in providing adequate support to flexible structures, especially in tight spaces where placement and compaction of more traditional backfill material would be problematic. Challenging situations such as placing bedding under haunches and backfilling between closely spaced parallel structures can be simplified or enhanced by using selfcompacting materials.

The most common materials used are either open-graded, angular aggregates or specially proportioned cementitious mixtures. Conventional CLSM mixtures usually consist of

Khalid Abdel-Rahman

Khalid@igth.uni-hannover.de

Institute for Geotechnical Engineering, Leibniz University of Hannover, Appelstr 9A, 30167 Hannover, Germany water, cement, fly ash or other similar products and fine or coarse aggregates or both. Selection of materials should be based on availability, cost, specific application and the necessary characteristics of the mixture, including flowability, strength, excavatability and density.

The main purpose of the investigations presented here is the comparison of bending moments of rigid and flexible pipes in sand or CLSM, taking the effect of hardening of CLSM into account.

\section{Previous investigations on behavior of buried pipelines}

CLSM is a self-compacted, cementitious material, which was widely known as flowable fill until American Concrete Institute Committee 229 documented its name as CLSM [2]. The CLSM is primarily used as a backfill material in lieu of compacted backfill and has become a popular material for projects such as void fill, foundation support, bridge approaches and conduit bedding [8]. CLSM, with different additives such as cement and fly ash, has been demonstrated, by many researchers, to be an effective bedding material for 
pipelines due to the self-compacting behavior and strength hardening $[5,10]$.

Although several studies were conducted on the analysis of buried pipes using soil-pipe interaction theories (e.g., [9, 12] a limited number of investigations have explored the performance of pipes buried in controlled low-strength material (CLSM) by numerical simulation.

McGrath [9] made a study on the pipe-soil interaction during backfilling. Diverse backfilling materials were used at varying compaction levels. Several soil box tests and field tests were conducted on steel, concrete and plastic pipes to compare the results for the different backfilling materials, trench conditions and bedding materials. Suleiman et al. [12] investigated the effects of large deflection behavior on buried plastic pipes. This study compared the small deflection analysis theory results by using culvert analysis and design (CANDE) software with the large deflection analysis theory.

Zhang et al. [14] developed a kinematic hardening model for pipeline-soil interactions under various loading conditions, and they conducted experimental tests using calcareous sandy soil. The developed hardening model required 13 different material parameters. Tian and Cassidy [13] modified the model developed by Zhang et al. [14] and introduced three plasticity models that could be used to simulate pipe-soil interactions numerically. Further study should be conducted to show the efficiency of the developed model by Tian and Cassidy [13] on buried steel pipes in different trench conditions.

Different CLSM materials were investigated experimentally and numerically by Arsic [3]. He investigated standard filling materials and CLSM materials in (1:1) experimental model. Then, a numerical model using ABAQUS was developed to predict the behavior of pipelines embedded in CLSM for different trench dimensions. Based on his results, the pipeline regulations were adopted and modified for CLSM.

Bellaver [4] developed a three-dimensional (3D) nonlinear finite element model of steel pipe coupled with CLSM and compacted soil. The finite element model consisted of the pipe and soil interaction during the staged construction of embedment and backfill. The numerical model was used to predict pipe performance under varying backfill and loading conditions.

Staged construction modeling of steel pipes buried in CLSM was investigated by Dezfooli et al. [7]. The results of field tests were compared with 3D nonlinear numerical model. The comparison of the results indicates that the finite element model is capable of predicting the deflection of the buried steel pipes in different backfilling and trench configurations.

Abdel-Rahman et al. [1] developed FEM using ABAQUS to simulate the behavior of pipelines embedded in self-compaction materials. The computations were done taking the hardening process and shrinkage of selfcompacting material into consideration.

Summarizing, only a limited number of investigations exist. In none of these studies, the effect of hardening process of self-compacting materials in the numerical modeling has been considered.

\section{Properties of self-compacting materials}

The properties of CLSM cross the boundaries between soils and concrete. CLSM is manufactured from materials similar to those used to produce concrete and is placed from equipment in a fashion similar to that of concrete. The properties of CLSM are affected by the constituents of the mixture and the proportions of the ingredients in the mixture. In the following, the main features will be explained briefly.

\section{Hardening process}

One of the most important aspects for CLSM is the hardening process which describes the dependency of $E$-modulus and Poisson's ratio $(v)$ on time. Figure 1 shows the development of $E$-modulus of CLSM with time. In the first days, the $E$-modulus is very small almost 10.0 MPA, then it increases gradually to reach 80.0 MPA after 7 days and finally 80.0 MPA after 28 days (4 weeks), and it remains almost constant. Simultaneously, the Poisson's ratio ( $v)$ decreases from 0.48 (CLSM behaves like a fluid) at the starting point of hardening and decreases gradually to reach after 7 days 0.12 ; then, it increases slightly to its final value 0.20 which corresponds to the solid state materials like concrete. The dependency of these parameters [E-modulus and Poisson's ratio $(v)]$ will be implemented via a subroutine for the numerical modeling of CLSM.

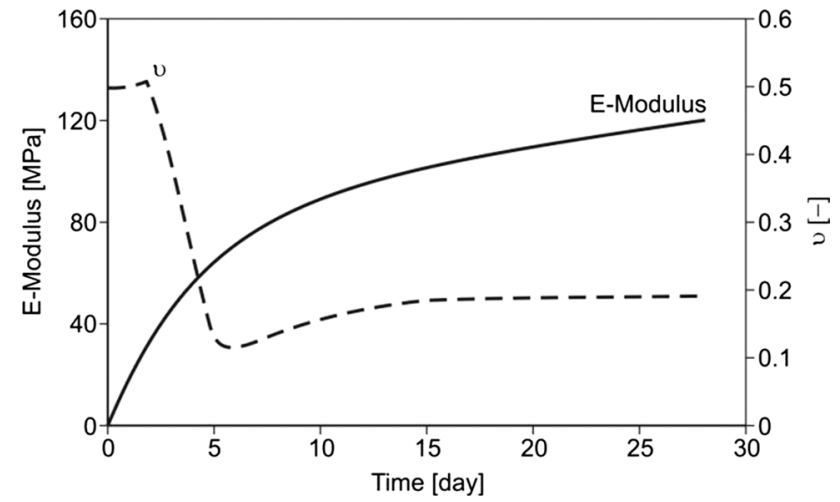

Fig. 1 Dependency of $E$-modulus and Poisson's ratio ( $v$ ) on time [3] 


\section{Shear strength}

Since engineering applications of CLSM as a substitute to conventional compacted fill are growing, it is getting more important to measure the shear strength parameters for CLSM properties either direct measurement or by developing correlations between geotechnical testing results. The shear strength properties of CLSM are important and can be measured using both a direct shear test and a triaxial shear apparatus. Controlled low-strength materials (CLSMs) considered in the numerical investigations have an internal friction angle ranging from $30.0^{\circ}$ to $40.0^{\circ}$ degrees and the cohesion ranging from 60.0 up to $90.0 \mathrm{kN} / \mathrm{m}^{2}$ after the hardening process of 28 days [3].

\section{Flowability}

Flowability is very important property which guarantees the construction process of CLSM. It is the property that distinguishes CLSM from other fill materials. It enables the materials to be self-leveling; to flow into and readily fill a void; and be self-compacting without the need for conventional compacting equipment. This property represents a major advantage of controlled low-strength materials compared with the conventional fill materials that must be mechanically placed in layers and compacted using different compaction equipments.

\section{Shrinkage process}

The shrinkage of controlled low-strength materials (CLSM) is a very critical aspect. Compared to concrete, CLSM typically has a very high water-cement ratio and water content that may cause after drying shrinkage. Based on our experimental investigations [6], the shrinkage of CLSM was about to $0.1 \%$ till $0.3 \%$.

Some shrinkage cracks may appear after the hardening process. However, they do not affect the structural integrity of the material for most applications and were not considered in the presented numerical modeling.

\section{Finite element modeling}

For the investigation of the behavior of pipelines embedded in sand and self-compacting materials, a two-dimensional (2D) numerical model was developed. The finite element program ABAQUS [11] was used for the numerical analysis.

\section{Numerical model}

A two-dimensional (2D-plane strain) finite element model was developed. The main aim was to calculate the vertical and horizontal deformation of the soil and to investigate the deformation response (bending moment) of a pipe with a diameter of $0.30 \mathrm{~m}$ once embedded in sandy soil and once embedded in self-compacting material. The dimensions of the numerical model used in the analysis are shown in Fig. 2. The elements used to model the soil and CLSM are sixnoded and eight-noded plane strain (CPE6 and CPE8) elements, while beam elements (B22) have been used to simulate the pipelines to be able to calculate the bending moment in the pipelines (Fig. 3). In this study, the embedment depth

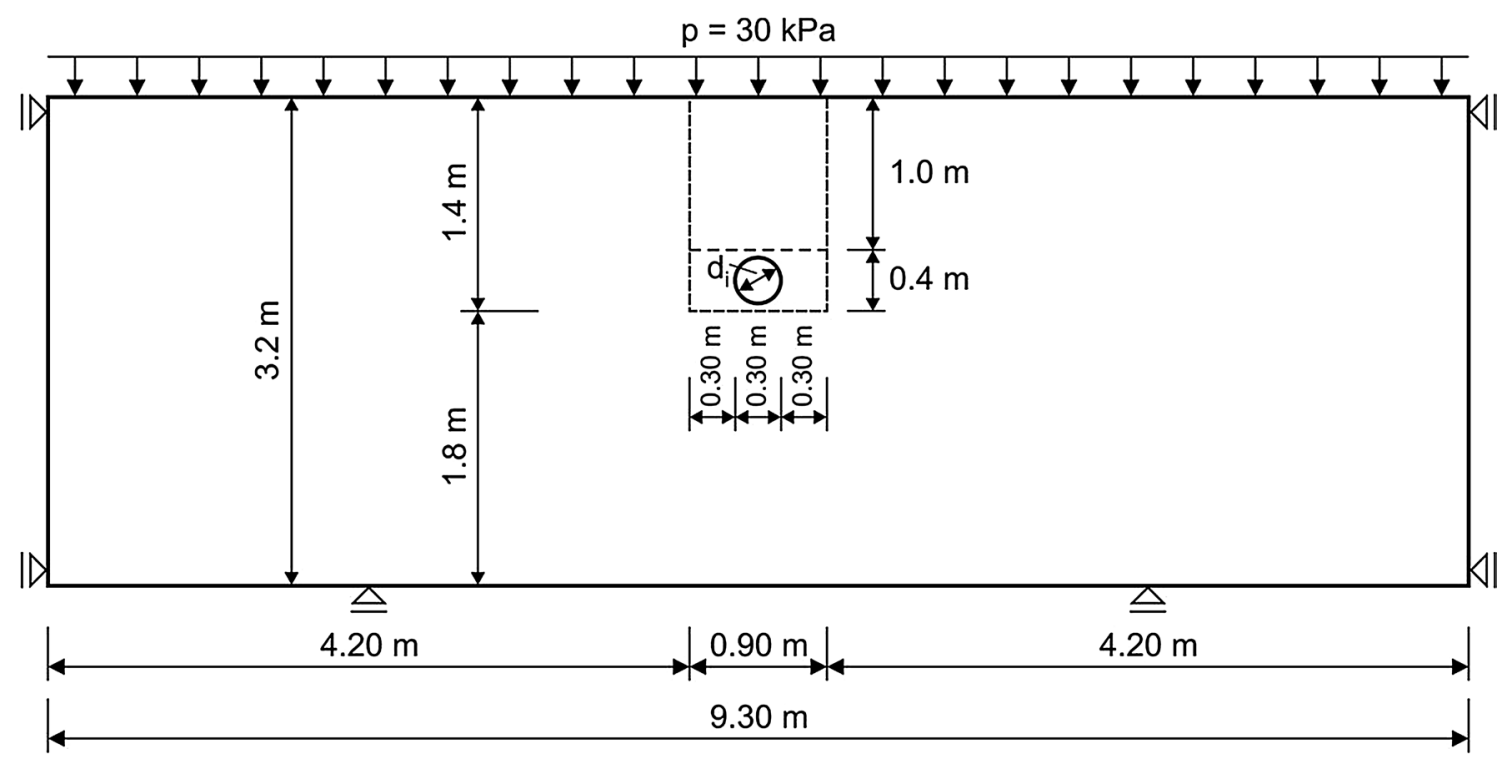

Fig. 2 Dimensions of the numerical model 


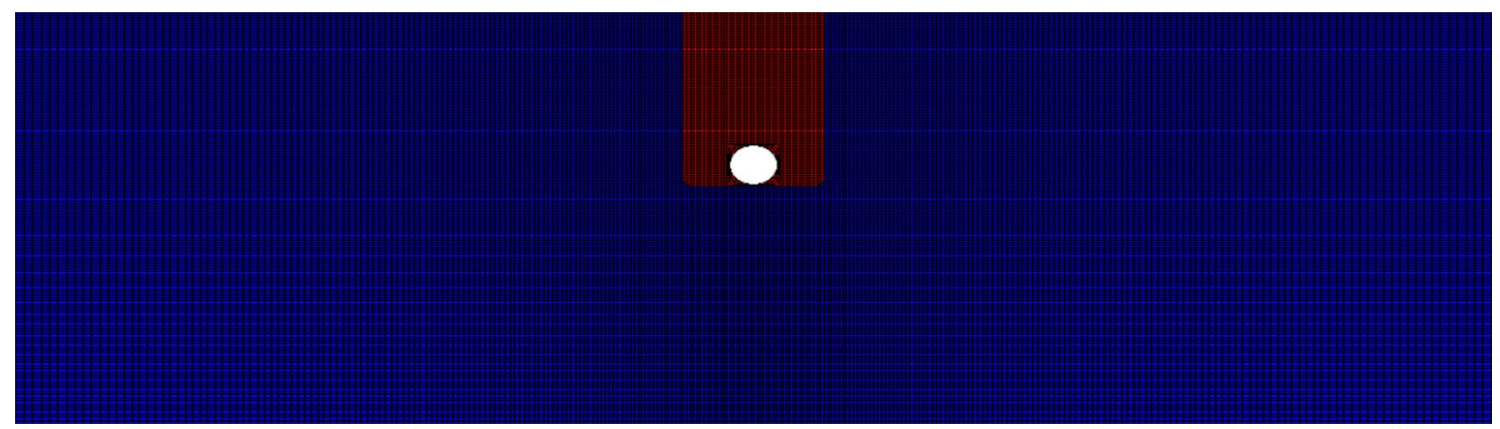

Fig. 3 Finite element mesh (trench is red marked)

(h) was set $1.0 \mathrm{~m}$ and the trench width $(b)$ was chosen to be $0.90 \mathrm{~m}$.

The dimension of the numerical model was varied by different trails, and we came finally to the conclusion that the numerical model should be extended horizontally from both sides min. four times the excavation width $(3.60 \mathrm{~m})$ and should also be extended vertically beneath the pipe min. the double of the excavation width $(1.80 \mathrm{~m})$. The final overall dimension of the numerical model was set to $9.30 \mathrm{~m} * 3.20 \mathrm{~m}$. With these model dimensions, the calculated behavior of the pipe is anticipated to be not affected by the boundary conditions.

To investigate the mesh dependency, different mesh designs (coarse, medium and fine) were adopted until the final mesh (no. of elements $=39,574$, no. of nodes $=119,347$ and DOFs $=237,122$ ) presented in Fig. 3 was used for the following investigations. The main purpose was to eliminate any mesh dependency of the obtained results.

\section{Constitutive model}

One of the most important issues in geotechnical numerical modeling is the choice of the suitable constitutive material model which represents the stress-strain behavior of the investigated material. An elasto-plastic material law with Mohr-Coulomb failure criterion was used to describe the behavior of the sandy soil and also the behavior of the selfcompacting materials. Mohr-Coulomb constitutive model is not a sophisticated material model with the same stiffness for loading and reloading paths, but for the planned investigation, Mohr-Coulomb is sufficient enough as one of the important aspects is the hardening process of CLSM, which was implemented in the numerical model, and also, the modeling procedure is monotonic without unloading or reloading stages.

According to the pipeline regulations, the pipe trench should be divided into four parts: $E_{1}$ above the pipeline, $E_{2}$ around the pipeline in the trench, $E_{3}$ the soil outside the trench and $E_{4}$ the soil part beneath the pipe outside the trench (Fig. 4). For each part, different soil properties should be adopted according to the investigated problem.

The material properties adopted for the subsoil outside the trench (part $E_{3}$ and $E_{4}$ ) were varied to investigate their effect on the behavior of the pipelines embedded in CLSM (Table 1). These parameters have a negligible effect on the pipelines.

In the case of sandy soil, for the elastic region of Mohr-Coulomb material model, E-modulus and Poisson's ratio are required. For the plastic region, the internal angle of internal friction $\left(\varphi^{\prime}\right)$, angle of dilatation $(\psi)$ and cohesion $(c)$ will be implemented (Table 1). The following table summarizes the main material parameters required for the different parts.

Regarding controlled low-strength material (CLSM), the time dependency for both $E$-modulus and Poisson's ratio is implemented as shown in Fig. 1, whereby for simplicity reasons the other material parameters (internal angle of friction, angle of dilatation and cohesion) required for Mohr-Coulomb model are kept constant and are listed in Table 2.

In order to investigate the effect of pipe stiffness on the overall behavior, two different pipe materials will be modeled in this paper. The first one is a rigid pipe made of concrete and

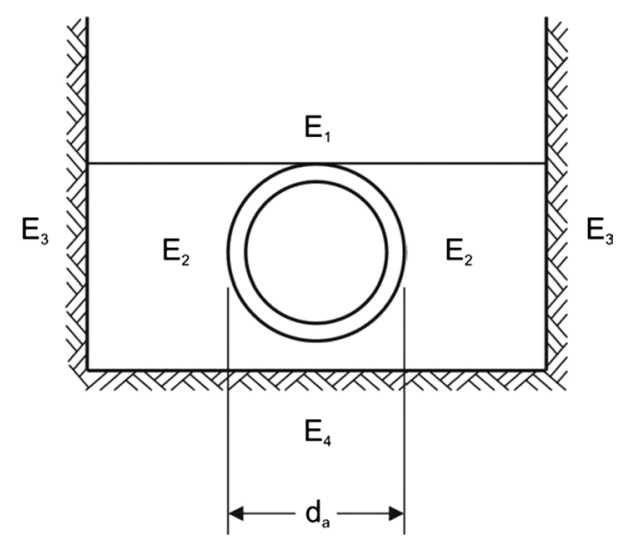

Fig. 4 Pipeline and the different trench parts $\left(E_{1}, E_{2}, E_{3}\right.$ and $\left.E_{4}\right)$ 
Table 1 Material properties for the filling sandy material

\begin{tabular}{llllllr}
\hline Zone & $\gamma\left(\mathrm{kN} / \mathrm{m}^{3}\right)$ & $E(\mathrm{MPa})$ & $v(-)$ & $\mathrm{C}^{\prime}\left(\mathrm{kN} / \mathrm{m}^{2}\right)$ & $\varphi^{\prime}\left({ }^{\circ}\right)$ & $\psi\left({ }^{\circ}\right)$ \\
\hline$E_{1}$ & 18.0 & 30.0 & 0.25 & 1.0 & 30.0 & 1.0 \\
$E_{2}$ & 18.0 & 25.0 & 0.25 & 1.0 & 30.0 & 1.0 \\
$E_{3}$ & 18.0 & 50.0 & 0.25 & 1.0 & 35.0 & 5.0 \\
$E_{4}$ & 18.0 & 80.0 & 0.25 & 1.0 & 40.0 & 10.0 \\
\hline
\end{tabular}

Table 2 Material properties for the filling CLSM

\begin{tabular}{ll}
\hline Unit weight $\gamma$ & $18.0\left(\mathrm{kN} / \mathrm{m}^{3}\right)$ \\
Internal friction angle $\varphi^{\prime}$ & $35.0^{\circ}$ \\
Dilatation angle $\psi$ & $5.0^{\circ}$ \\
Cohesion $c^{\prime}$ & $80\left(\mathrm{kN} / \mathrm{m}^{2}\right)$ \\
\hline
\end{tabular}

the second one is a flexible PVC pipe. Table 3 summarizes the main material properties [3] adopted for the numerical modeling:

\section{Contact behavior}

To describe the behavior of the embedded pipes accurately, two different contact pairs are adopted in the numerical model. The first contact pair (CP1) describes the contact behavior between the pipe and the surrounding soil in the trench. The second contact pair (CP2) is implemented to simulate the vertical sliding between the excavation part (trench) and the surrounding soil on both sides of the trench (Fig. 5). This contact pair (CP2) is essential to predict the behavior of the filling material in the trench compared to the surround soil. For both of the contact pairs, an elasto-plastic contact model was used.

For this contact model, the maximum frictional shear stress is calculated from the normal stress and the friction coefficient on the sliding surface. For the first contact pair (CP1), the friction coefficient $\mu=0.431(\mu=\tan (2 / 3 \varphi))$ was adopted, while for the second contact pair (CP2) the friction coefficient $\mu=0.70(\mu=\tan (\varphi))$ was implemented. For full mobilization of the limit frictional stress, the relative displacement (elastic slip) between the pile and the surrounding soil was set to $\Delta u_{\mathrm{el}, \mathrm{slip}}=2.0 \mathrm{~mm}$.

\section{Numerical modeling procedure}

The modeling process for the pipes embedded in sandy soil should reflect the construction process in reality, which is very complicated. The modeling process will be simplified and executed stepwise. Firstly, the primary stress state under the own weight of the lower soil medium located beneath the pipeline $\left(E_{4}\right)$ is generated. In the subsequent steps, different soil layers are activated to simulate the construction steps (Fig. 5).

In the following step, both sides of the trench $\left(E_{3}\right)$ will be activated by putting horizontal boundary conditions on the vertical sides to secure the stability of the trench before filling. Consequently, the pipeline is embedded in the middle part $\left(E_{2}\right)$ and the contact pairs (CP1 and CP2) will be activated. This step represents the first stage of the trench filling around the pipe. Then, the upper part $\left(E_{1}\right)$ in the trench will be added with the corresponding contact pair (CP2) between the trench and the surrounding soil. Finally, the vertical surcharge $\left(p=30 \mathrm{kN} / \mathrm{m}^{2}\right)$ is applied on the top surface of the model as traffic load.

For the pipelines embedded in self-compacting material (CLSM), more steps are required in order to simulate the
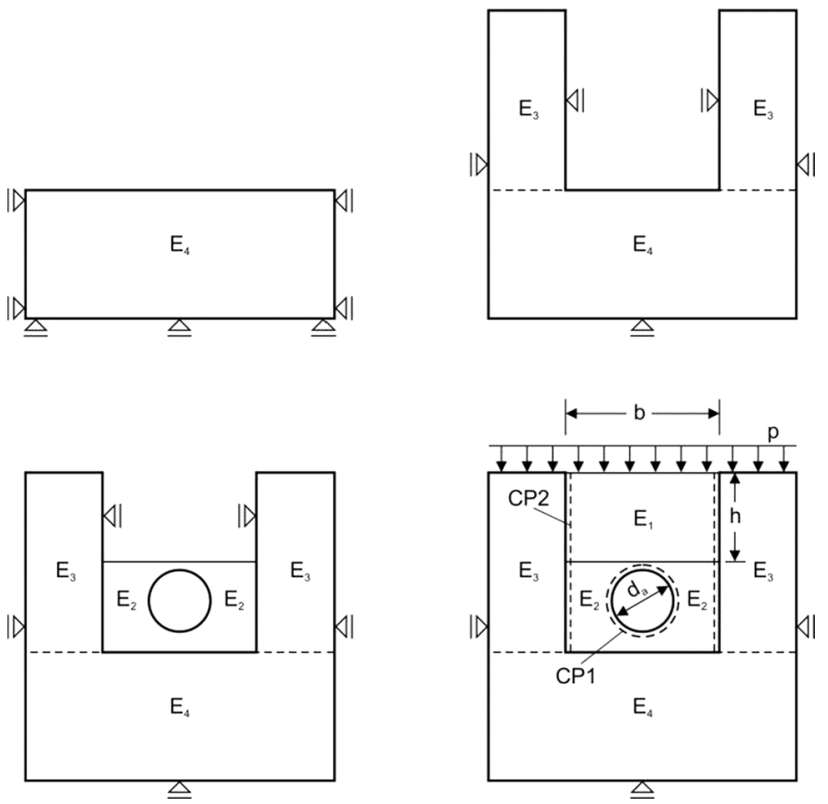

Fig. 5 Steps of the numerical modeling
Table 3 Material properties for different pipeline materials

\begin{tabular}{llrrlll}
\hline Material & $\gamma\left(\mathrm{kN} / \mathrm{m}^{3}\right)$ & $E(\mathrm{MPa})$ & $G(\mathrm{MPa})$ & $v(-)$ & $D(\mathrm{~m})$ & Thickness $(\mathrm{m})$ \\
\hline Concrete & 24.0 & $31,000.0$ & $12,900.0$ & 0.2 & 0.3 & 0.04 \\
PVC-U & 14.0 & 2250.0 & 833.0 & 0.35 & 0.3 & 0.01 \\
\hline
\end{tabular}


hardening process taking the dependency of Elastic modulus $(E)$ and Poisson ratio $(v)$ (Fig. 1) into consideration. Here, two more steps are added to describe the behavior self-compacting material (CLSM) after 7 days and 28 days before applying finally the vertical surcharge on the top on the model $\left(p=30 \mathrm{kN} / \mathrm{m}^{2}\right)$.

This modeling procedure is different compared to the trench excavation, but this concept simplifies the numerical modeling and gives very reasonable results for comparison reasons between conventional filling materials and selfcompacting materials (CLSM).

\section{Numerical modeling results}

The numerical modeling deals with the behavior of rigid and flexible pipes embedded in granular material and in selfcompacting material "CLSM" taking the effect of hardening process into consideration. The vertical soil deformation and embedded pipe behavior including the vertical stress, horizontal stress and bending moments will be presented and evaluated.

\section{Concrete pipe embedded in sand}

Figure 6 shows the vertical soil deformation (U2) in the last step after applying the surcharge $\left(p=30.0 \mathrm{kN} / \mathrm{m}^{2}\right)$. The maximum settlement reaches almost $2.40 \mathrm{~mm}$ at the ground surface, whereby in the trench due to the concrete pipe the settlement is about $1.80 \mathrm{~mm}$. Also, there is a relative displacement along $\mathrm{CP} 2$ between the soil domain and the trench.

In order to investigate the deformation response of the pipeline, the bending moment around the pipeline embedded in sand after applying the surcharge loading ( $p=30.0 \mathrm{kN} /$ $\mathrm{m}^{2}$ ) is presented in Fig. 7. The $x$-axis shows the angle measure from the crown (zero at the pipe top, $90^{\circ}$ at the horizontal pipeline axis and $180^{\circ}$ at the bottom of the pipeline).

The bending moment in the pipe at the crown is $0.22 \mathrm{kNm} / \mathrm{m}$, decreases gradually to zero by almost $45.0^{\circ}$ measured from the crown and then increases up to

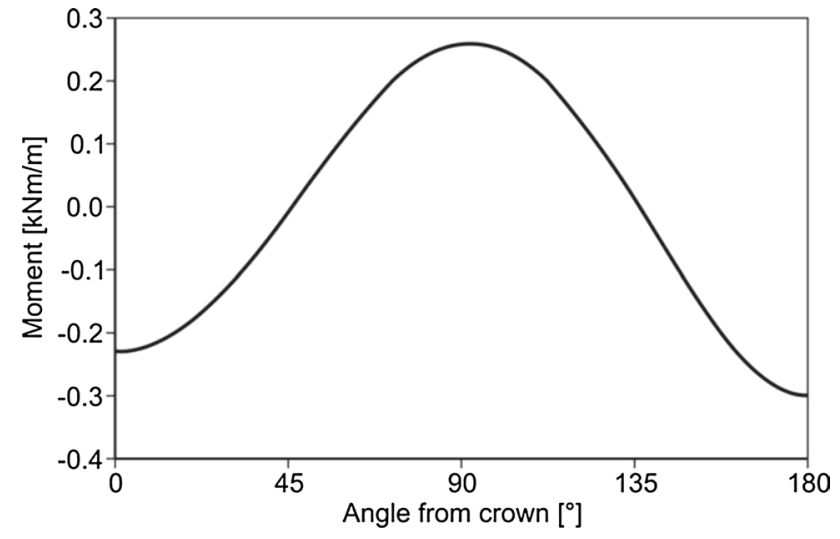

Fig. 7 Bending moment around rigid pipeline embedded in sand $\left(p=30.0 \mathrm{kN} / \mathrm{m}^{2}\right)$

$0.26 \mathrm{kNm} / \mathrm{m}$ at $90^{\circ}$. In the lower half of the pipe from $90^{\circ}$ up $180^{\circ}$, we have a similar bending moment distribution but the maximum value reaches finally $0.32 \mathrm{kNm} / \mathrm{m}$ at the bottom. This distribution indicates that the pipe was compressed in the vertical direction and extended in the horizontal direction which is a typical behavior for pipeline embedded in the sandy soil.

\section{Concrete pipe embedded in CLSM}

In case of self-compacting material, a similar distribution of vertical displacement in the numerical model was obtained (Fig. 8). The maximum settlement at the ground surface reaches $2.20 \mathrm{~mm}$, and in the trench, the vertical deformation of $1.1 \mathrm{~mm}$ was obtained which is lower than the sandy soil. This is due to the hardening process of the CLSM, which leads to higher stiffness modulus compared to the sand.

The bending moment in the pipeline is based on the change in the vertical and horizontal contact stress acting on the pipeline due to the hardening process of CLSM. This is explained firstly in detail.

Figures 9 and 10 show the distribution of contact stress (normal and shear stress) between the pipeline and the surrounding soil "CLSM" projected vertically to give the
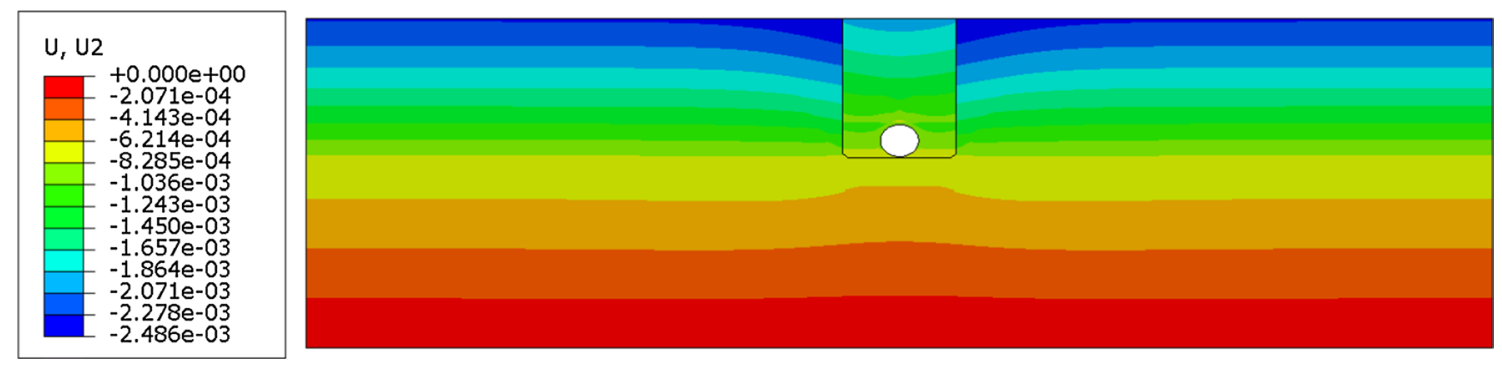

Fig. 6 Vertical displacement distribution in the soil domain 

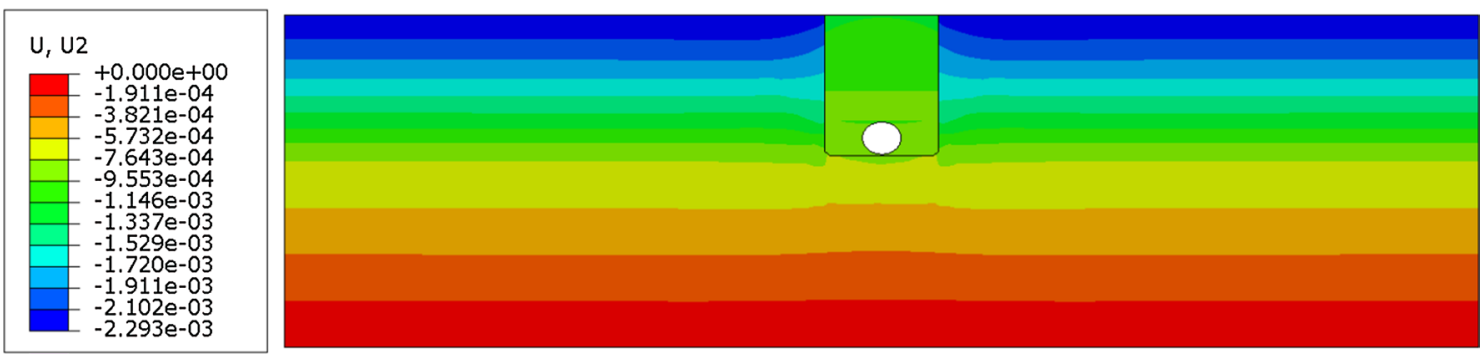

Fig. 8 Vertical displacement distribution in the soil domain

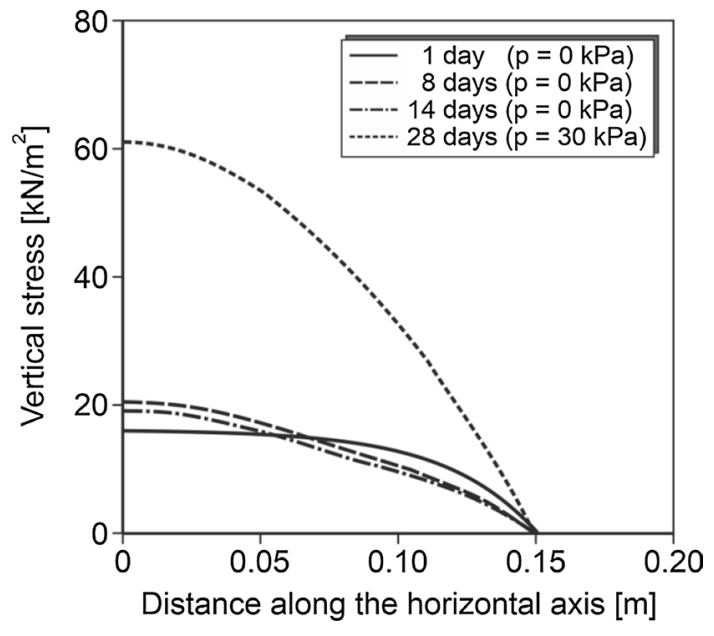

Fig. 9 Vertical stress around rigid pipeline embedded in CLSM

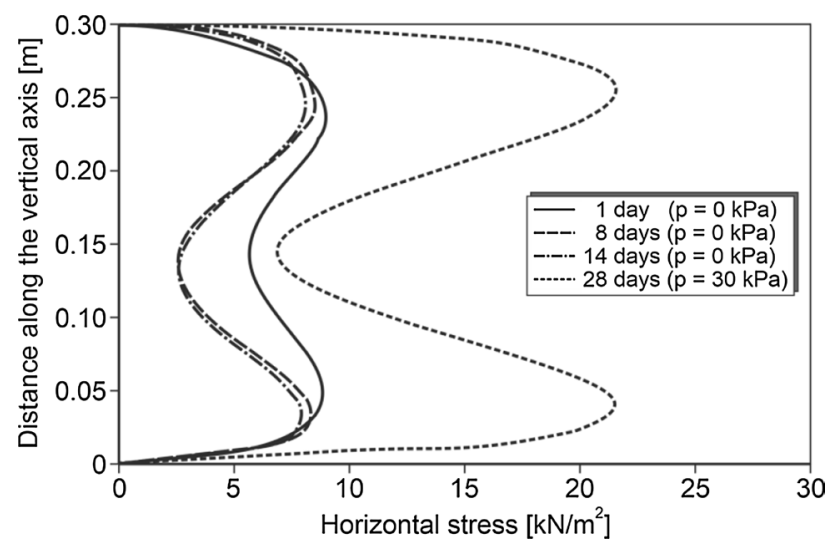

Fig. 10 Horizontal stress around rigid pipeline embedded in CLSM

vertical stress component (Fig. 9) and horizontally to give the horizontal stress component acting on the pipe (Fig. 10). The vertical stress distribution as shown in Fig. 9 has its maximum value on the vertical (symmetry axis) of the pipe and the minimum value at the end of pipe ( $x=$ radius of the pipe $=0.15 \mathrm{~m}$ ). In the first 2 weeks, there is a redistribution of the vertical stress and it decreases slightly with the

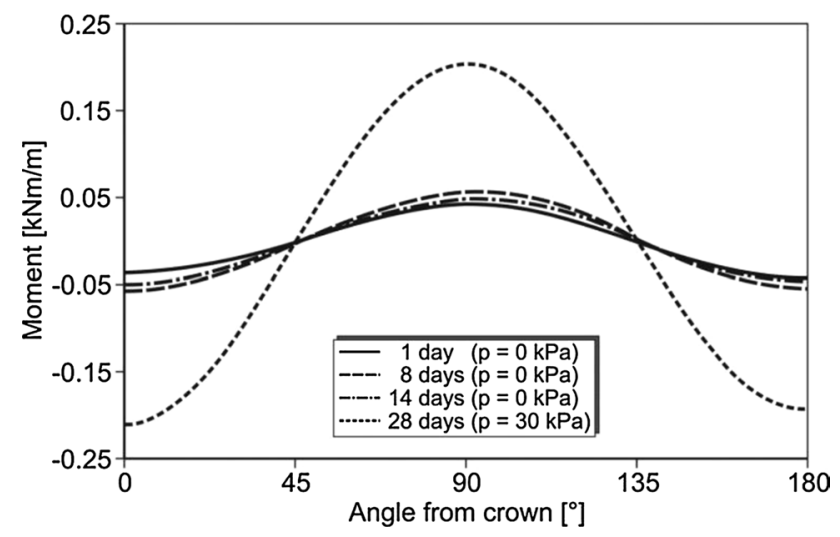

Fig. 11 Bending moment around rigid pipeline embedded in CLSM

hardening process due the change in the material properties (increase in the soil stiffness and decrease in the Poisson's ratio). By applying the traffic load of $30.0 \mathrm{kN} / \mathrm{m}^{2}$, the vertical stress reaches a maximum value of $61.0 \mathrm{kN} / \mathrm{m}^{2}$ at the top.

Figure 10 shows the horizontal stress component projected along the diameter of the pipeline $(D=0.30 \mathrm{~m})$. At the crown and the bottom of the pipe, the horizontal stress component is equal to zero as the main stress component is the vertical stress (Fig. 9).

Then, the horizontal stress increases gradually to reach its maximum value at almost an angle of $45.0^{\circ}$ measured from the vertical axis. As before, in the first 2 weeks there is redistribution of the horizontal stress acting on the pipe and it decreases at $90.0^{\circ}$ from 8.0 to $4.5 \mathrm{kN} / \mathrm{m}^{2}$. Then, by applying the traffic loading, the horizontal stress component reaches $21.0 \mathrm{kN} / \mathrm{m}^{2}$ at almost $45.0^{\circ}$ and then reduces to $8.50 \mathrm{kN} / \mathrm{m}^{2}$ at $90.0^{\circ}$.

These two previous figures will help us to derive the bending moment around the pipeline. The bending moment distribution is shown in Fig. 11.

In the first days up to 14 days, the bending moment is small (ca. $0.05 \mathrm{kNm} / \mathrm{m}$ ) and almost constant around the pipe line. With the hardening process and the application of the surcharge $\left(p=30.0 \mathrm{kN} / \mathrm{m}^{2}\right)$, the pipe will be deformed (Fig. 8) and consequently the bending moment increases 
up to a maximum value of $0.21 \mathrm{kNm} / \mathrm{m}$ at the crown, in the middle and at the bottom. These values are smaller than in the case of sandy soil. This can be explained as the CLSM has a higher stiffness than the sand and therefore a less pipe deformation, which leads to a smaller bending moment in the pipeline.

\section{Flexible pipe embedded in sand}

For comparison reasons, a flexible pipe (PVC-U) was also modeled. Figure 12 shows the vertical soil deformation (U2) in the last step. The maximum settlement reaches almost $2.40 \mathrm{~mm}$ at the ground surface, whereby in the trench due to the flexible pipe the settlement is about $2.0 \mathrm{~mm}$. These values are little bit higher than the previous case (rigid pipe) as the flexile pipe has a smaller stiffness than the rigid one.

The bending moment around flexible pipeline embedded in sand after applying the surcharge loading $(p=30.0 \mathrm{kN} /$ $\mathrm{m}^{2}$ ) is presented in Fig. 13. As the flexible pipe was compressed in the vertical direction and extended in the horizontal direction, a similar bending moment distribution to the rigid pipeline will be obtained. The bending moment in the pipe at the crown is $0.21 \mathrm{kNm} / \mathrm{m}$ and decreases gradually to zero by almost $45.0^{\circ}$ measured from the crown and then increases up to $0.22 \mathrm{kNm} / \mathrm{m}$ at $90^{\circ}$. In the lower half of the pipe from $90^{\circ}$ up $180^{\circ}$, we have a similar bending moment distribution but the maximum value reaches finally $0.29 \mathrm{kNm} / \mathrm{m}$ at the bottom.

The higher values are located at the crown, at the horizontal axis of the pipe line and at the bottom of the pipe line. These values are smaller than the previous case (rigid pipeline), as the stiffness of flexible pipe is lower than the stiffness of the rigid pipe (Table 3 ).

\section{Flexible pipe embedded in CLSM}

In case of self-compacting material, a similar distribution of vertical displacement in the numerical model was obtained (Fig. 14). The maximum settlement at the ground surface reaches $2.20 \mathrm{~mm}$, and in the trench, a vertical deformation almost $1.50 \mathrm{~mm}$ was obtained. As the flexible

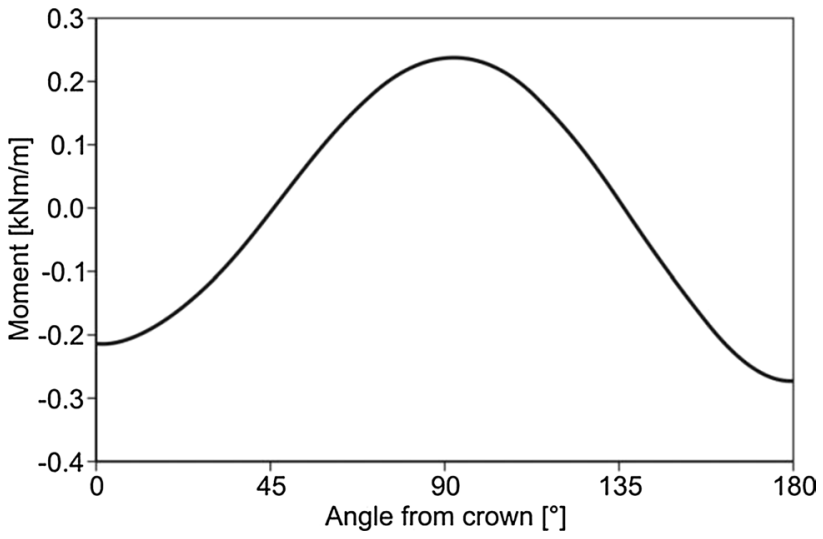

Fig. 13 Bending moment around flexible pipeline embedded in sand $\left(p=30.0 \mathrm{kN} / \mathrm{m}^{2}\right)$

pipe has as a smaller stiffness than the rigid one, this leads to higher settlement compared to the rigid pipe (Fig. 8).

Figures 15 and 16 show the distribution of contact stress between the pipe and the surrounding soil "CLSM" projected vertically to give the vertical stress component and horizontally to give the horizontal stress component acting along the flexible pipeline.

Similar as before, the vertical stress distribution (Fig. 15) has its maximum value on the vertical (symmetry axis) of the pipe and the minimum value at the end of pipe $(x=$ radius of the pipe $=0.15 \mathrm{~m})$. In the first 2 weeks, there is a slight decrease in the vertical stress and the maximum value reached is $18.0 \mathrm{kN} / \mathrm{m}^{2}$. Under the traffic loading, the maximum value at the piper vertical axis is $48.0 \mathrm{kN} / \mathrm{m}^{2}$. These values are smaller than the previous rigid pipeline.

Figure 16 shows the horizontal stress component drawn along the diameter of the pipeline $(D=0.30 \mathrm{~m})$. During the hardening process, the horizontal stress component deceases by about $11 \%$ in the first 8 days. By applying the vertical surcharge, the horizontal stress component increases gradually to reach its maximum value of $18.0 \mathrm{kN} / \mathrm{m}^{2}$ at $45.0^{\circ}$ and then reduces to $11.0 \mathrm{kN} / \mathrm{m}^{2}$ at $90.0^{\circ}$. These values are smaller compared to the other values obtained by rigid pipe.
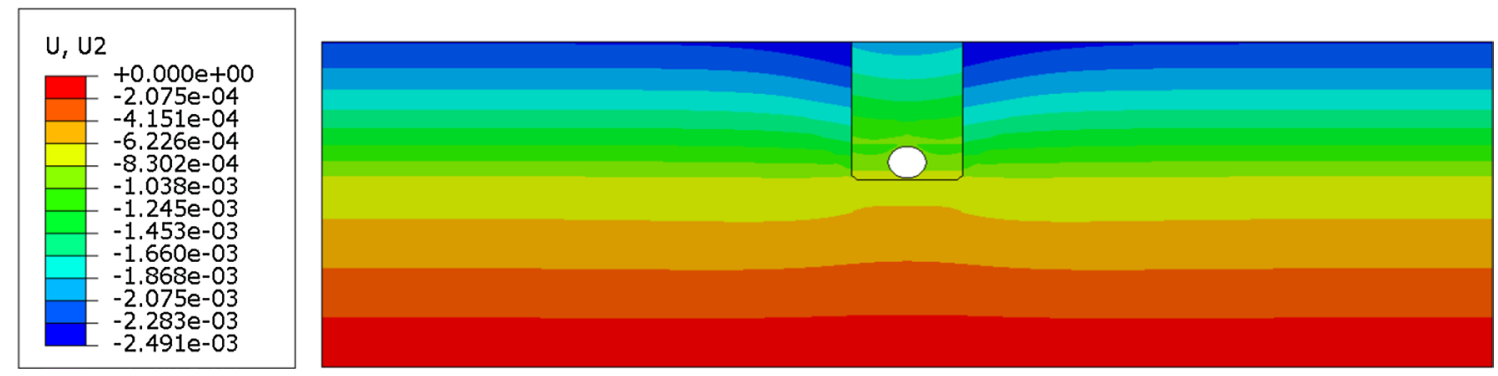

Fig. 12 Vertical displacement distribution in the soil domain 

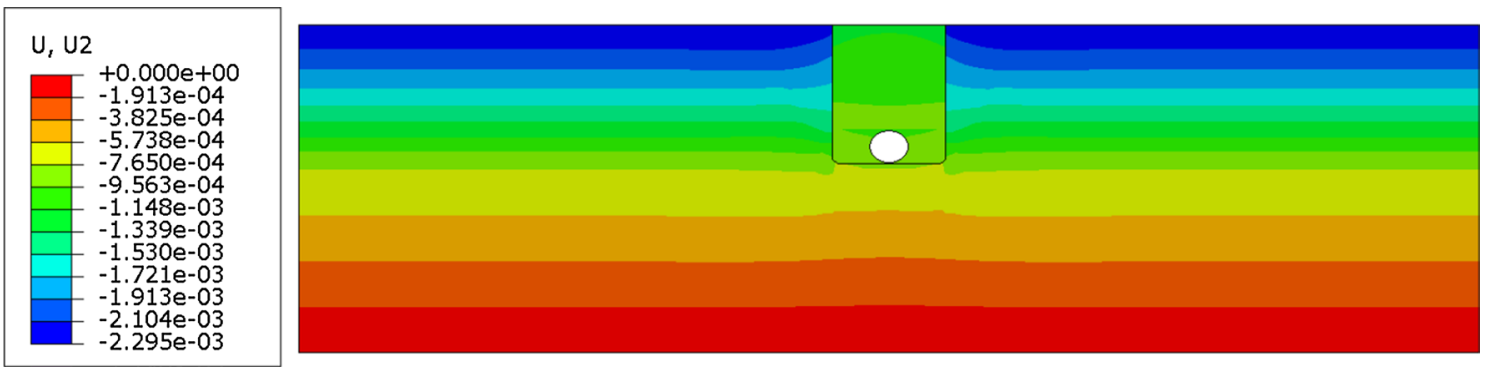

Fig. 14 Vertical displacement distribution in the soil domain

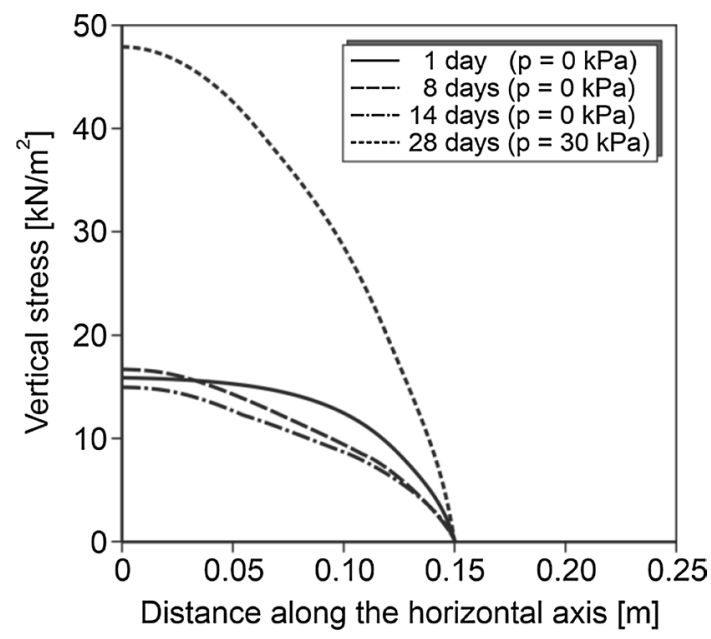

Fig. 15 Vertical stress around flexible pipeline embedded in CLSM

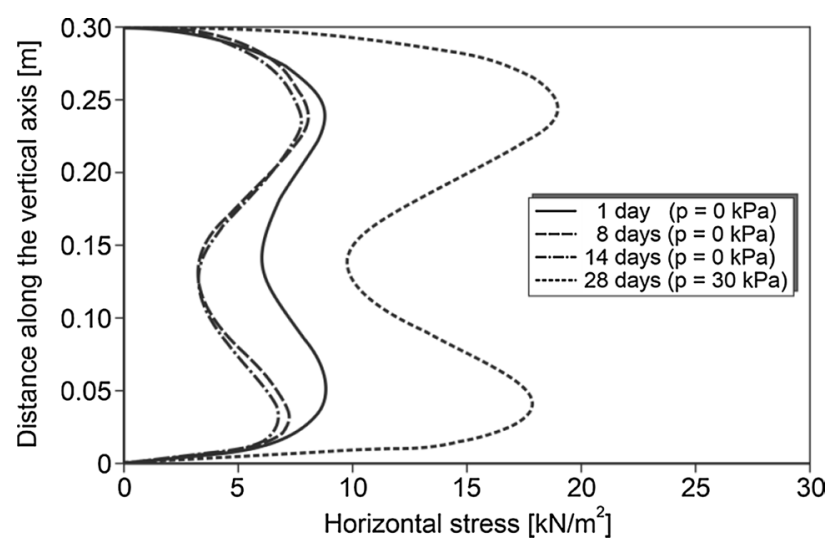

Fig. 16 Horizontal stress around flexible pipeline embedded in CLSM

Finally, the bending moment distribution is shown in Fig. 17. Similar to the rigid pipe, up to 14 days, the horizontal and the vertical stress are similar, which means that the bending moment is relatively small and constant all around the pipe. With the hardening process and the application of the vertical surcharge stress $\left(30.0 \mathrm{kN} / \mathrm{m}^{2}\right)$, the bending

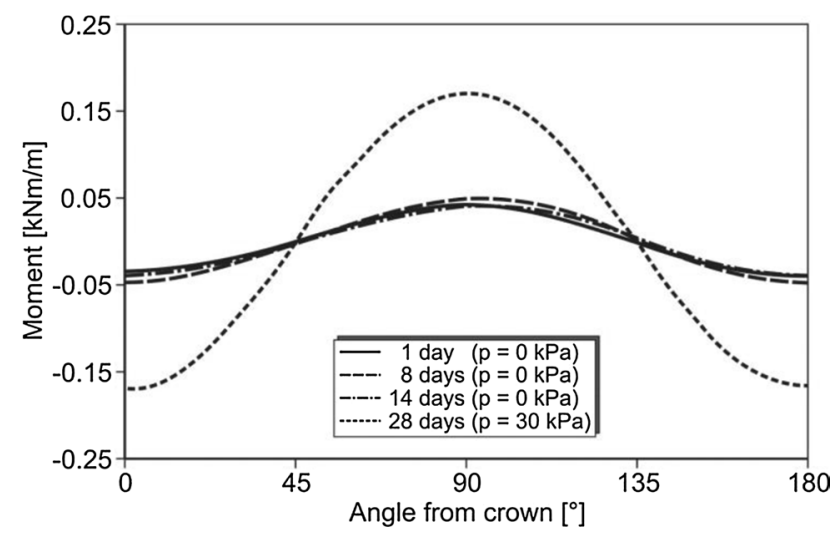

Fig. 17 Bending moment distribution for flexible pipeline embedded in CLSM

moment increases up to $0.17 \mathrm{kNm} / \mathrm{m}$, which is lower than the previous case (rigid pipe) and also lower than the embedded case in sandy soil. Finally, these results show that the hardening of self-compacting materials (CLSMs) affect positively the behavior of rigid as well as the flexible pipelines.

\section{Conclusions}

For the investigations presented, a FEM was developed to simulate the behavior of pipelines embedded in sandy soil and in self-compaction materials. The computations were executed taking the hardening process of self-compaction material into consideration. It is evident for the investigated case that the bending moments are smaller and the overall behavior is therefore better than by the use of the standard filling material. Also the hardening process of the CLSM has a minor effect on the vertical stress and horizontal stress components. Another advantage is the reduced quality of compaction below and beneath the pipe in usual fill materials. In subsequent investigations, further parametric studies will be carried out for different trench widths and embedment depths. 
Acknowledgements Open Access funding provided by Projekt DEAL.

Open Access This article is licensed under a Creative Commons Attribution 4.0 International License, which permits use, sharing, adaptation, distribution and reproduction in any medium or format, as long as you give appropriate credit to the original author(s) and the source, provide a link to the Creative Commons licence, and indicate if changes were made. The images or other third party material in this article are included in the article's Creative Commons licence, unless indicated otherwise in a credit line to the material. If material is not included in the article's Creative Commons licence and your intended use is not permitted by statutory regulation or exceeds the permitted use, you will need to obtain permission directly from the copyright holder. To view a copy of this licence, visit http://creativecommons.org/licenses/by/4.0/.

\section{References}

1. Abdel-Rahman K, Achmus M, Gerlach T (2017) Behavior of pipelines embedded in self-compactions materials under traffic loads. In: International conference GeoMEast, Sharm El-Sheikh, Egypt, July 15-19, 2017

2. American Concrete Institute (1994) Committee 229, Controlled low-strength materials (CLSM). ACI 229R-94 report

3. Arsic Igor (2009) Über die Bettung von Rohrleitungen in Flüssigböden. Institute for Soil Mechanics and Geotechnical Engineering, University of Bochum, Germany (in German)

4. Bellaver F (2013) Large diameter steel pipe field test using controlled low-strength material and staged construction modeling using 3-D nonlinear finite element analysis. M.Sc. thesis, University of Texas at Arlington, Arlington, TX
5. Boschert J, Butler J (2013) CLSM as pipe bedding: computing predicted load using the modified Marston equation. ASCE Pipelines 2013:1201-1212

6. Buhr F (2015) Untersuchung zur Schwind-bzw. Schrumpfneigung von Flüssigböden im Zuge der Erhärtung. Bachelor thesis, IGtH, Hannover (unpublished) (in German)

7. Dezfooli M, Abolmaali A, Park Y, Bellaver F (2015) Staged construction modeling of steel pipes buried in CLSM using 3D nonlinear finite-element analysis. Int J Geomech 15(6):1-13

8. Folliard KJ, Trejo D, Sabol SA, Leshchinsky D (2008) Development of a recommended practice for use of controlled low-strength material in highway construction, NCHRP 597 report, pp 5-39

9. McGrath TJ (1998) Pipe-soil interactions during backfill placement. Ph.D. dissertation, University of Massachusetts, Amherst, MA

10. Rajah S, McCabe M, Plattsmier J (2012) Classification and specification of bedding and backfill for buried pipelines. In: ASCE pipelines 2012: innovations in design, construction and maintenance, pp 940-951

11. Simulia (2018) User's manual, version 6.18. Simulia, Providence, RI, USA

12. Suleiman MT, Lohnes RA, Wipf TJ, Klaiber FW (2002) Analysis of deeply buried flexible pipes. Transp Res Rec 1849:124-133

13. Tian Y, Cassidy MJ (2008) Modeling of pipe-soil interaction and its application in numerical simulation. Int J Geomech (ASCE) 4(8):213-229

14. Zhang J, Stewart DP, Randolph MF (2002) Kinematic hardening model for pipeline-soil interaction under various loading conditions. Int J Geomech (ASCE) 4(2):419-446 